\title{
Characterization of carbapenem-resistant Acinetobacter baumannii in Shanghai and Hong Kong
}

Acinetobacter spp. have been increasing in significance in hospitals as colonizers and pathogens, especially of immunocompromised hosts, patients in intensive care units and those with serious underlying diseases (Bergogne-Berezin \& Towner, 1996). Within the genus, organisms within the Acinetobacter baumannii complex are particularly significant as opportunistic pathogens. The A. baumannii complex includes genospecies 1,2, 3 and 13, which can only be identified by amplified rDNA restriction analysis (Vaneechoutte et al., 1995), and of which genospecies 2 most commonly causes hospital infections (Bergogne-Berezin \& Towner, 1996). Treatment of acinetobacter infections is often complicated by their resistance to multiple antibiotics. Although carbapenems have remained more active than other antimicrobial agents and resistance to this class of antibiotics is still rare, carbapenem-resistant Acinetobacter spp. have increased in prevalence during the past few years (Afzal-Shah \& Livermore, 1998). These strains were initially reported to be carbapenem resistant due to a mechanism other than production of $\beta$-lactamases, but $\beta$-lactamase-mediated resistance is commonly detected in recent strains (Clark, 1996; Héritier et al., 2005). The first $\beta$-lactamase reported in carbapenem-resistant A. baumannii was ARI-1, now renamed OXA-23 (Donald et al., 2000).

The carbapenem-hydrolysing OXA enzymes sequenced so far belong to three clusters. The first cluster comprises the OXA-23 and OXA-27 enzymes, with $99 \%$ amino acid homology; the second cluster includes the OXA-24, OXA-25 and OXA-26 enzymes, which share $98 \%$ homology; the homology between these two clusters is $60 \%$ (Héritier et al., 2005). The third cluster, with OXA-58 as the only member, shares $<50 \%$ homology with the other two clusters.
In this study, we aimed to determine the prevalence of carbapenem-resistant Acinetobacter baumannii (IMRAB) in Shanghai and Hong Kong and to detect genes encoding carbapenem-hydrolysing $\beta$-lactamases by PCR in IMRAB isolates.

A total of 214 non-duplicate A. baumannii clinical isolates were collected from Renji Hospital, Shanghai $(n=175)$, and the Prince of Wales Hospital, Hong Kong ( $n=39$ ), from August 2002 to August 2003. Strains from Shanghai were isolated from clinical specimens that included sputum, wound, abscess, bile, urine and blood, and strains from Hong Kong were isolated from blood cultures only. All isolates were identified by the API 20NE system (API systems) together with other standard biochemical tests. They were further identified to genospecies by amplified $\mathrm{rDNA}$ restriction analysis (ARDRA) (Vaneechoutte et al., 1995).

MICs of antibiotics (Table 1) were determined by an agar dilution method using Mueller-Hinton agar (Oxoid) according to the recommendation of the National Commmittee for Clinical Laboratory Standards (2003).

Strains were typed by macro-restriction analysis of chromosomal DNA with ApaI (Amersham Biosciences) using PFGE on a CHEF-DR apparatus (Bio-Rad) with pulses ranging from 5 to $35 \mathrm{~s}$ at a voltage of $6 \mathrm{~V} \mathrm{~cm}^{-1}$ at $14{ }^{\circ} \mathrm{C}$ for $32 \mathrm{~h}$. DNA bands were photographed with a Gel Documentation System (Pharmacia Biotech) and analysed using Bionumerics version 2.5 software. Following conversion, normalization with molecular mass markers, and background subtraction, comparison matrices of the Dice coefficient were generated and dendrograms were constructed using the unweighted pair group method by arithmetic means (UPGMA).
Strains were also typed by repetitive extragenic palindromic PCR (REP-PCR) using primer pair REP1 and REP2 according to Martín-Lozano et al. (2002). Strains with similar profiles (up to two-band difference) were assigned to the same DNA group. A Dice coefficient of $\geqslant 80 \%$ was used to denote closely related isolates (Tenover et al., 1995).

Crude $\beta$-lactamases were extracted from bacteria by sonication, and pIs were determined by isoelectric focusing on PAGplates (Pharmacia Biotech, $\mathrm{pH}$ range 3.5-9.5) in a Multiphor II System (Pharmacia-LKB) (Matthew et al., 1975). The following $\beta$-lactamases of known $\mathrm{pI}$ were used as markers: TEM-1 (pI 5.4), TEM-2 (pI 5·6), TEM-3 (pI 6·3), K1 (pI 6·5), OXA-1 (pI 7·4), SHV-1 (pI 7·6), OXA-2 (pI 7·7), SHV-4 (pI 7·8) and P99 (pI 8·2).

The extracted DNA was screened by PCR for the presence of $b l a_{\text {OXA-23-specific }}$ and $b l a_{\mathrm{OXA}-24}$-related sequences

(Afzal-Shah et al., 2001), and $b l a_{\mathrm{TEM}^{-}}$and $b l a_{\mathrm{PER}}$-related sequences (primer pairs $5^{\prime}$ GAGTATTCAACATTTCCGTGTC-3' and 5' -TAATCAGTGAGGCACCTATCTC-3', and $5^{\prime}$-ATGAATGTCATTATAAAAGC- ${ }^{\prime}$ and 5 '-AATTTGGGCTTAGGGCAGAA-3', respectively, were used) (Jiang et al., 2002).

Of the 214 acinetobacters tested, 12 were resistant to imipenem and meropenem (IMRAB) (MICs 8 to $>64 \mu \mathrm{g} \mathrm{ml}^{-1}$ ). They were identified to be A. baumannii; 10 belonged to genospecies 3 and two to genospecies 2 . They were also resistant to ampicillin-sulbactam $\left(\mathrm{MIC} \geqslant 16 / 8 \mu \mathrm{g} \mathrm{ml}^{-1}\right)$; piperacillin and ticarcillin $\left(\mathrm{MIC} \geqslant 128 \mu \mathrm{g} \mathrm{ml}^{-1}\right.$ ); piperacillin-tazobactam (MIC 64/4 to $>128 / 4 \mu \mathrm{g} \mathrm{ml}^{-1}$ ); ticarcillin-clavulanate (MIC > 128/2 $\mu \mathrm{g} \mathrm{ml}^{-1}$ ); cefoperazone, ceftazidime and cefepime (MIC $\geqslant 32 \mu \mathrm{g}$ $\left.\mathrm{ml}^{-1}\right)$; gentamicin $\left(>64 \mu \mathrm{g} \mathrm{ml}^{-1}\right)$ and cotrimoxazole (MIC 16 to $>64 \mu \mathrm{g} \mathrm{ml}^{-1}$ ) (Table 1). The MIC of 
Table 1. Characteristics and in vitro antimicrobial susceptibilities of 12 clinical isolates of $A$. baumannii

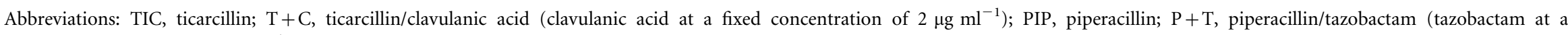


imipenem; MEM, meropenem; GM, gentamicin; AMK, amikacin; CIP, ciprofloxacin; LEV, levofloxacin; SXT, cotrimoxazole.

\begin{tabular}{|c|c|c|c|c|c|c|c|c|c|c|c|c|c|c|c|c|c|c|c|c|c|c|c|}
\hline \multirow{2}{*}{$\begin{array}{l}\text { Strain } \\
\text { number }\end{array}$} & \multirow{2}{*}{ Organism $^{\star}$} & \multirow{2}{*}{$\begin{array}{l}\text { PFGE } \\
\text { type }\end{array}$} & \multirow{2}{*}{$\begin{array}{l}\text { REP- } \\
\text { PCR } \\
\text { type }\end{array}$} & \multicolumn{3}{|c|}{$\mathrm{PCR} \dagger$} & \multicolumn{17}{|c|}{ MIC $\left(\mu \mathrm{g} \mathrm{ml}^{-1}\right)$ (breakpoint for susceptible strains in parentheses) $\ddagger$} \\
\hline & & & & OXA & PER & TEM & $\begin{array}{c}\text { TIC } \\
(\leqslant 16)\end{array}$ & $\begin{array}{c}T+C \\
(\leqslant 16 / 2)\end{array}$ & $\begin{array}{l}\text { PIP } \\
(\leqslant 16)\end{array}$ & $\begin{array}{c}P+T \\
(\leqslant 16 / 4)\end{array}$ & $\begin{array}{l}\text { CFP } \\
(\leqslant 16)\end{array}$ & $\begin{array}{c}C+S \\
(\leqslant 16 / 16) \S\end{array}$ & $\begin{array}{c}A+S \\
(\leqslant 8 / 4)\end{array}$ & SUL & $\begin{array}{l}\text { CAZ } \\
(\leqslant 8)\end{array}$ & $\begin{array}{l}\mathrm{CPE} \\
(\leqslant 8)\end{array}$ & $\begin{array}{l}\text { IMP } \\
(\leqslant 4)\end{array}$ & $\begin{array}{l}\text { MEM } \\
(\leqslant 4)\end{array}$ & $\begin{array}{c}\text { GM } \\
(\leqslant 4)\end{array}$ & $\begin{array}{l}\text { AMK } \\
(\leqslant 16)\end{array}$ & $\begin{array}{c}\text { CIP } \\
(\leqslant 1)\end{array}$ & $\begin{array}{l}\text { LEV } \\
(\leqslant 2)\end{array}$ & $\begin{array}{l}\text { SXT } \\
(\leqslant 2)\end{array}$ \\
\hline 3 & ABAU G 3 & A3 & 1 & + & + & - & $>128$ & $>128 / 2$ & 128 & $64 / 4$ & $>64$ & $8 / 8$ & $16 / 8$ & 8 & $>64$ & 32 & 8 & 8 & $>64$ & 8 & 2 & $0 \cdot 5$ & $>64$ \\
\hline 16 & ABAU G 3 & A3 & 1 & + & + & - & $>128$ & $>128 / 2$ & 128 & $64 / 4$ & $>64$ & $16 / 16$ & $32 / 16$ & 16 & $>64$ & 64 & 16 & 16 & $>64$ & 64 & $0 \cdot 5$ & $0 \cdot 12$ & 32 \\
\hline 25 & ABAU G 3 & A3 & 1 & + & + & - & $>128$ & $>128 / 2$ & 128 & $64 / 4$ & $>64$ & $8 / 8$ & $16 / 8$ & 8 & $>64$ & 64 & 8 & 8 & $>64$ & 64 & 64 & $0 \cdot 25$ & 64 \\
\hline 126 & ABAU G 3 & A3 & 1 & + & + & - & $>128$ & $>128 / 2$ & 128 & $64 / 4$ & $>64$ & $16 / 16$ & $32 / 16$ & 16 & $>64$ & 64 & 16 & 16 & $>64$ & 64 & 1 & $0 \cdot 25$ & 64 \\
\hline 166 & ABAU G 3 & Al & 1 & + & + & - & $>128$ & $>128 / 2$ & 128 & $64 / 4$ & $>64$ & $16 / 16$ & $32 / 16$ & 16 & $>64$ & 64 & 16 & 8 & $>64$ & 32 & $0 \cdot 5$ & $0 \cdot 12$ & 64 \\
\hline 176 & ABAU G 3 & Al & 2 & + & + & - & $>128$ & $>128 / 2$ & 128 & $64 / 4$ & $>64$ & $16 / 16$ & $32 / 16$ & 16 & $>64$ & 64 & 16 & 8 & $>64$ & 32 & $0 \cdot 5$ & $0 \cdot 12$ & 16 \\
\hline 182 & ABAU G 3 & A2 & 2 & + & + & - & $>128$ & $>128 / 2$ & 128 & $64 / 4$ & $>64$ & $16 / 16$ & $32 / 16$ & 16 & $>64$ & 64 & 16 & 8 & $>64$ & 32 & $0 \cdot 5$ & $0 \cdot 12$ & 64 \\
\hline 190 & ABAU G 2 & B1 & 3 & + & + & + & $>128$ & $>128 / 2$ & $>128$ & $>128 / 4$ & $>64$ & $16 / 16$ & $32 / 16$ & 16 & $>64$ & $>64$ & 32 & 32 & $>64$ & 64 & 64 & 8 & $>64$ \\
\hline 191 & ABAU G 3 & $\mathrm{~A} 1$ & 2 & + & + & - & $>128$ & $>128 / 2$ & 128 & $64 / 4$ & $>64$ & $16 / 16$ & $32 / 16$ & 16 & $>64$ & 64 & 8 & 8 & $>64$ & 32 & $0 \cdot 5$ & 1 & 64 \\
\hline 192 & ABAU G 3 & A4 & 2 & + & + & - & $>128$ & $>128 / 2$ & 128 & $64 / 4$ & $>64$ & $32 / 32$ & $64 / 32$ & 32 & $>64$ & 64 & 16 & 16 & $>64$ & 32 & $0 \cdot 5$ & 1 & 32 \\
\hline 193 & ABAU G 2 & B2 & 3 & + & + & + & $>128$ & $>128 / 2$ & $>128$ & $>128 / 4$ & $>64$ & $32 / 32$ & $64 / 32$ & 32 & $>64$ & $>64$ & 32 & 32 & $>64$ & $>64$ & 64 & 8 & $>64$ \\
\hline 108132 & ABAU G 3 & B3 & 3 & + & - & + & $>128$ & $>128 / 2$ & $>128$ & $>128 / 4$ & $>64$ & $32 / 32$ & $64 / 32$ & 32 & 64 & 64 & 32 & $>64$ & $>64$ & 16 & 16 & 4 & 32 \\
\hline
\end{tabular}

*ABAU G, A. baumannii genospecies.

$†$ PCR products obtained after amplification using OXA-, PER- or TEM-specific primers. +, PCR product produced; -, PCR product not produced.

¥According to the recommendation of the Clinical and Laboratory Standards Institute (2005) (formerly known as the National Committee for Clinical Laboratory Standards, NCCLS).

§The breakpoint of cefoperazone/sulbactam is not provided by Clinical and Laboratory Standards Institute $(2005)$ and was taken as $\leqslant 16 / 16 \mu \mathrm{g} \mathrm{l}^{-1}$.
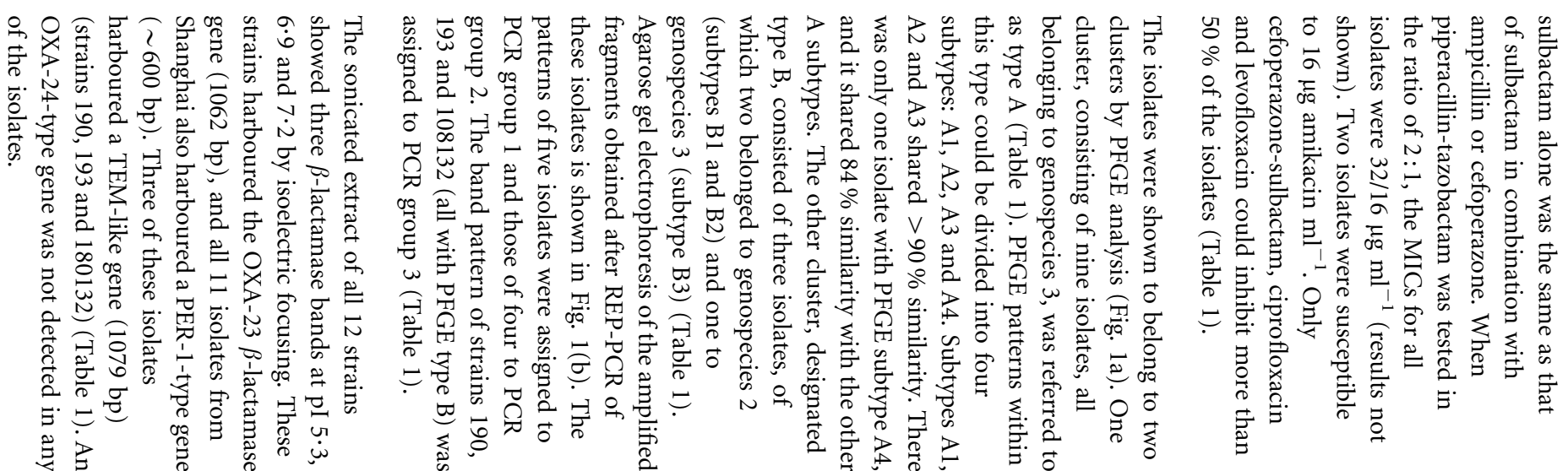
(a)



(b)

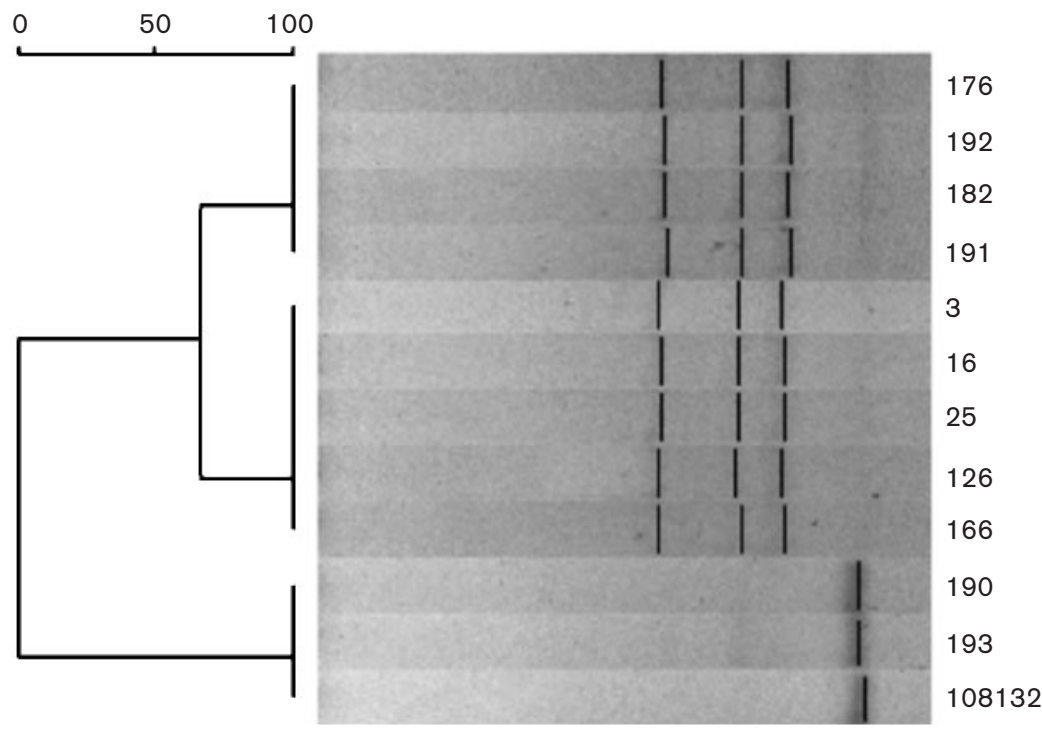

Fig. 1. (a) Dendrogram showing results of Dice coefficient based on PFGE of restricted DNA fragments of all 12 isolates. Nine isolates were assigned to type $A$, with three isolates within subtype $A 1$ (166, 176 and 191), one each within subtypes $A 2$ and $A 4$ (182 and 192, respectively) and four within subtype $A 3$ (3, 16, 25 and 126). Three isolates were assigned to subtypes B1, B2 and B3 (190, 193 and 108132, respectively) within type B. (b) Dendrogram showing results of Dice coefficient based on REP-PCR of all 12 isolates. Five isolates were assigned to PCR group 1 (3, 16, 25, 126 and 166), four to group 2 (176, 182, 191 and 192) and three to group 3 (190, 193 and 108132).

inhibitor, e.g. piperacillin-tazobactam and cefoperazone-sulbactam, was more active than the $\beta$-lactam alone. Sulbactam alone has an antibacterial effect on Acinetobacter strains, and $\beta$-lactams in combination with sulbactam were found to be effective against this group of organisms.
In order to investigate the source of infection and the route of spread of the infecting organism, several phenotypic and molecular typing methods have been used. Although an antibiogram may alert us to the emergence of a multiply resistant A. baumannii outbreak, distinguishing between strains with slight differences in their resistance profiles may be difficult. Therefore, PFGE of chromosomal DNA restriction fragments and PCR fingerprinting have been used to investigate nosocomial A. baumannii outbreaks (Dimopoulou et al., 2003). By using PFGE 
and REP-PCR, we demonstrated the spread of IMRAB strains in a Shanghai hospital during a period of 1 year. These isolates belonged to two different clones, as evidenced by PFGE analysis, and all except one belonged to the same genospecies.

Several class B and D $\beta$-lactamases have been reported to be responsible for carbapenem resistance in acinetobacters (Héritier et al., 2005). Three different $\beta$-lactamases were produced by our IMRAB strains: a TEM-like enzyme, a PER-1-type $\beta$-lactamase, and an OXA-derived enzyme.

All our 12 IMRAB isolates harboured an OXA-23 gene, 11 of which, all from Shanghai, also harboured a PER-1-type gene as demonstrated by PCR. Two isolates from Shanghai (strains 190 and 193) and one from Hong Kong (strain 108132) harboured a TEM-type gene as well. These three IMRAB isolates belonged to PFGE type $\mathrm{B}$, and were different from the other nine isolates, which were of PFGE type A and did not harbour the TEM-type gene. The MICs of imipenem and meropenem (MIC 32 to $>64 \mu \mathrm{g} \mathrm{ml}^{-1}$ ) for the three strains that harboured an OXA-23, TEM-like and/or PER-1-type gene were higher than those for other isolates.

The results of this study showed that both OXA-23- and PER-1-type $\beta$-lactamases were prevalent among IMRAB in Shanghai and had already spread among different clones. The PER-1-type $\beta$-lactamase has also been shown to be prevalent in Turkey (Vahaboglu et al., 1997). Whether the presence of a TEM-like gene augments the hydrolytic activity of OXA-23 remains to be determined. Interestingly, the strain isolated from Hong Kong that did not have the PER-1-type gene (strain 108132) was more resistant to meropenem than strains with this gene.

Since carbapenem-resistant $A$. baumannii strains are highly resistant to $\beta$-lactams, aminoglycosides and fluoroquinolones, their emergence and dissemination deserve great attention. Continuous surveillance should be carried out to monitor the spread of these strains.

\section{Chun Mei Ying, ${ }^{1}$ Thomas K. W. Ling, ${ }^{2}$ Ching Ching Lee ${ }^{2}$ and Julia M. Ling ${ }^{2}$}

\section{${ }^{1}$ Department of Microbiology, Shanghai Second Medical University, Renji Hospital, Shanghai, People's Republic of China \\ ${ }^{2}$ Department of Microbiology, The Chinese University of Hong Kong, The Prince of Wales Hospital, Shatin, New Territories, Hong Kong Special Administrative Region, People's Republic of China}

Correspondence: Julia M. Ling (meilunling@cuhk.edu.hk)

Afzal-Shah, M. \& Livermore, D. M. (1998) Worldwide emergence of carbapenem-resistant Acinetobacter spp. J Antimicrob Chemother 41, 576-577.

Afzal-Shah, M., Woodford, N. \& Livermore, D. M. (2001). Characterization of OXA-25, OXA-26, and OXA-27, molecular class D $\beta$-lactamases associated with carbapenem resistance in clinical isolates of Acinetobacter baumannii. Antimicrob Agents Chemother 45, 583-588.

Bergogne-Berezin, E. \& Towner, K. J. (1996). Acinetobacter spp. as nosocomial pathogens: microbiological, clinical, and epidemiological features. Clin Microbiol Rev 9, 148-165.

Clark, R. B. (1996). Imipenem resistance among Acinetobacter baumannii: association with reduced expression of a 33-36 KDa outer membrane protein. J Antimicrob Chemother 38, 245-251.

Clinical and Laboratory Standards Institute (2005). Performance Standards for Antimicrobial Susceptibility Testing: Fifteenth Informational Supplement M100-S15. Wayne, PA: Clinical and Laboratory Standards Institute.

Dimopoulou, I. D., Kartali, S. I., Kartalis, G. N., Manolas, K. I., Simopoulos, K. E., Vargemezis, B. A., Theodoropoulou-Rodiou, G., Bowler, I. C. \& Crook, D. W. (2003). Relationship between nosocomial Acinetobacter species occurring in two geographical areas (Greece and the UK). J Hosp Infect 54, 207-211.
Donald, H. M., Scaife, W., Amyes, S. G. B. \& Young, H. K. (2000). Sequence analysis of ARI1 , a novel OXA $\beta$-lactamase, responsible for imipenem resistance in Acinetobacter baumanni 6B92. Antimicrob Agents Chemother 44, 196-199.

Héritier, C., Poirel, L., Lambert, T. \& Nordmann, P. (2005). Contribution of acquired carbapenem-hydrolyzing oxacillinases to carbapenem resistance in Acinetobacter baumannii. Antimicrob Agents Chemother 49, 3198-3202.

Jiang, X., Yu, J. \& Hong, X. (2002). A clinical strain of Acinetobacter baumannii which produces OXA-23 carbapenemase and PER-1 type ESBLs. Shanghai J Med Lab Sci 17, 263-267.

Martín-Lozano, D., Cisneros, J. M., Becerril, B., Cuberos, L., Prados, T., Ortiz-Leyba, C. Cañas, E. \& Pachón, J. (2002). Comparison of a repetitive extragenic palindromic sequence-based PCR method and clinical and microbiological methods for determining strain sources in cases of nosocomial Acinetobacter baumannii bacteremia. J Clin Microbiol 40, 4571-4575.

Matthew, M., Harris, A. M., Marshall, M. \& Ross, G. W. (1975). The use of analytical isoelectric focusing for detection and identification of $\beta$-lactamases. J Gen Microbiol 88, 169-178.

National Commmittee for Clinical Laboratory Standards (2003). Methods for Dilution Antimicrobial Susceptibility Tests for Bacteria that Grow Aerobically, 6th edn. Approved standard M7-A6. Wayne, PA: National Commmittee for Clinical Laboratory Standards.

Tenover, F. C., Arbeit, R. \& Archer, G. (1995). Interpreting chromosomal DNA restriction patterns produced by pulsed-field gel electrophoresis: criteria for bacterial strain typing. J Clin Microbiol 33, 2233-2239.

Vahaboglu, H., Ozturk, R., Aygun, G. \& Coskunkan, F. (1997). Widespread detection of PER-1-type extended-spectrum $\beta$-lactamases among nosocomial Acinetobacter and Pseudomonas aeruginosa isolates in Turkey: a nationwide multicenter study. Antimicrob Agents Chemother 41, 2265-2269.

Vaneechoutte, M., Dijkshoorn, L., Tjernberg, I., Elaichouni, A., De Vos, P., Claeys, G. \& Vershraegen, G. (1995). Identification of Acinetobacter genomic species by amplified ribosomal DNA restriction analysis. J Clin Microbiol 33, 11-15. 